\title{
A critical review of recent trends in second language syllabus design and curriculum development
}

Rajaee Nia, Mahdi $\measuredangle$

Iran University of Science and Technology, Iran (mahdi.rajaeenia@gmail.com)

Abbaspour, Ehsan

Iran University of Science and Technology, Iran (eabbaspour@aol.com)

Zare, Javad

Iran University of Science and Technology, Iran (javadzare@lang.iust.ac.ir)

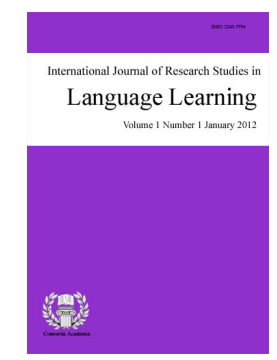

ISSN: $2243-7754$ Online ISSN: 2243-7762

OPEN ACCESS

\begin{abstract}
To date, numerous books and research articles have focused on the notion of syllabus design and curriculum development. Nevertheless, very few works have had an inclusive and concise look upon the issue. This paper is an account of current trends on syllabus design and curriculum development in Second Language Acquisition in the recent past decades. This is hopefully intended to offer a descriptive and critical interpretation of the existing syllabuses in the domain of language learning and teaching. After a brief introductory remark on curriculum and syllabus types, 13 of the most prominent syllabuses in SLA will be elaborated on separately. In pursuit of doing so, definition, rationale, merits, and drawbacks attributed to each syllabus will be touched upon. Although the emergence of some of these syllabi coincides with each other, while presenting them, it has been tried to follow a roughly chronological order of their emergence.
\end{abstract}

Keywords: syllabus design; curriculum development; second language acquisition 


\section{A critical review of recent trends in second language syllabus design and curriculum development}

\section{Introduction}

Etymologically syllabus means a 'label or 'table of contents'. Wilkins (1981) pointed out: "syllabuses are specification of the content of language teaching which have been submitted to some degree of structuring or ordering with the aim of making teaching and learning a more effective process". So far, there have been several approaches to syllabus design within literature. In essence, each type of syllabus offers alternative answers to the question: What does a learner of a new language need to know, and what does a learner need to be able to do with this knowledge? (Breen, 1987, p. 85). To design a syllabus is to decide what gets taught and in what order.

\subsection{Difference between Syllabus and Curriculum}

Nunan (1988) believes that curriculum is wider term as compared with syllabus. Curriculum covers all the activities and arrangements made by the institution throughout the academic year to facilitate the learners and the instructors whereas syllabus is limited to particular subject of a particular class.

\subsection{Types of syllabi}

Scholars have distinguished six different types of syllabi throughout the literature. Almost all the language teaching syllabi are amalgamations of two or more of the types defined below.

\subsubsection{Product-oriented versus process-oriented syllabuses}

Nunan (1988) that product-oriented syllabuses are those in which the focus is on the knowledge and skills which learners should gain as a result of instruction (the product or the end), while process syllabuses are those which focus on the learning experiencing themselves (the processes toward the end).

\begin{tabular}{|l|l|}
\hline \multicolumn{1}{|c|}{ Product-oriented } & \multicolumn{1}{c|}{ Process-oriented } \\
\hline Structural/Formal & Tasked-based \\
\hline Situational & Procedural \\
\hline Lexical & Negotiated \\
\hline Notional-Functional & Proportional \\
\hline & Content-based \\
\hline
\end{tabular}

Figure 1. Product/Process-oriented syllabi

\subsubsection{Analytic versus synthetic syllabuses}

Wilkins (1976) draws a distinction between synthetic and analytic types of syllabuses. A synthetic language teaching strategy is one in which the different parts of language are taught separately and gradually. Here, the acquisition is a process of accumulation of parts until the whole structure of language has been constructed. In contrast, analytic syllabuses are organized in terms of the purposes for which people intend to learn the language and the kinds of language performance that are necessary to fulfill those objectives.

\begin{tabular}{|l|l|}
\hline \multicolumn{1}{|c|}{ Analytic syllabuses } & \multicolumn{1}{c|}{ Synthetic syllabuses } \\
\hline Tasked-based & Structural \\
\hline Procedural & Situational \\
\hline Notional-functional [According to Wilkins (1976)] & Notional-functional [(According to Long \& Crooks (1992)) \\
\hline Content-based & \\
\hline Negotiated & \\
\hline
\end{tabular}

Figure 2. Analytic/Synthetic-oriented syllabi 


\subsubsection{Type A versus Type B syllabuses}

White (1988) recognizes two types of syllabuses namely Type A and Type B. According to him, Type A syllabi are concerned with what should be learned. Without considering who the learners may be or how languages are acquired, they determine a series of objectives and they 'pre-package' the language by dividing it into small, discrete units. They are product-oriented, so they evaluate the outcomes in terms of mastery of the language. All synthetic syllabi are considered Type A syllabi. Type B syllabi, on the contrary, are concerned with how the language is learned and how this language is integrated with learners' experiences. The different elements of the syllabus emerge from a process of negotiation between learners and teachers; they are oriented toward the process; and evaluation criteria are set by the learners themselves. As we will see later, procedural, process, and task-based syllabi are considered Type B syllabi despite their differences.

\section{Structural/Formal Syllabus}

Krahnke (1987) maintains that the structural syllabus is, doubtless, the most familiar of syllabus types. It has a long history, and a major portion of language teaching has been carried out using some form of it. The structural syllabus is based on a theory of language that assumes that the grammatical or structural aspects of language form are the most basic or useful. He further (p. 10) holds that a structural (or formal) syllabus is one in which the content of language teaching is a collection of the forms and structures, usually grammatical, of the language being taught.

\subsection{Rationales for the formal syllabus}

Breen (1987) sets forth three rationales:

$>$ The first argument is that it is well established and it is informed by a long tradition of linguistic analysis.

$>\quad$ The second major justification for the Formal syllabus is that it presents learners with a subject matter which is systematic and rule-governed. When we learn something new, the fact that we can begin to see patternedness and regularities within it will reduce the 'learning load' it demands of us.

$>$ A third justification for the Formal syllabus is that because the linguistic system is analyzable in certain ways, these analytical categories or schemas can be incorporated in a plan for teaching the system, and - further - it may be that the same analytical categories or schemas make it easier for the learner to uncover how the new language works. Such a syllabus calls upon the human capacity to be meta-linguistic; to reflect upon, talk about, and try to work out just how a language works.

\subsection{Merits}

Karanke (1987) mentions the Positive characteristics of Structural syllabus:

$>$ Structure or grammar is the most general component of communicative competence. Every utterance, if it is reasonably well-formed, involves a given structure, which can be used for variety of functions, situations, and meanings.

$>$ Its content is relatively easy to describe. Noun, verb, imperative, plural, and gerund are terms that are generally shared within the language profession, and there is general agreement about what they mean.

Structural knowledge is the most measurable components of the communicative competence. Because of the relative fitness of structural knowledge and its relatively clear definition, measurement tasks are easily prepared to determine how much students have not learned.

$>$ While structural knowledge does not seem to be used directly by learners, some evidence (Higgs \& 
Clifford, 1982) suggests that it can prevent later fossilization or cessation of learning. Generally, students who ultimately achieved high proficiency in a new language were students who had earlier received instruction in the form of the language.

$>$ Instruction in language structure offers a basis for teachers or others to provide learners with feedback on the accuracy of their production.

$>$ Structural syllabi are naturally value and culture-free.

\subsection{Drawbacks}

Apparently, the structural syllabus violates most, if not all, of the types of reward that should be catered for in foreign language teaching materials as suggested by Stevick (1972) which can be summarized on the following grounds:

$>$ Relevance of the content to the student's own language needs.

$>$ Completeness or inclusion of all the language necessary for the stated aims.

$>$ Authenticity of the materials both linguistically and culturally.

$>$ Satisfaction of the students with their day to day progress in the classroom.

$>$ Immediacy of the usage of the students has learned in the classroom.

Breen (1987) also mentions several notorious weaknesses associated with structural syllabi:

Dsability, applicability, or transferability of structural knowledge: Structural knowledge may be teachable, and there is some evidence (Hartwell, 1985) that is learnable, but there is almost no evidence that it affects behavior in language use to any great degree.

$>$ It can mislead learners into thinking they are learning a language when, in fact, they are learning facts or information about a language.

> Sequencing or grading problems: A strictly structural syllabus prevents students from producing structures they have not been taught. Either the students have to be severely limited or controlled in their use of the new language until the needed structures have been taught or their errors must be tolerated or ignored until the appropriate instruction appears in the sequence.

\section{Situational Syllabus}

Palmer and Hornby believed that a grammatical or structural syllabus was neither efficient, nor effective for language learning since this model offers language samples outside their social and cultural contexts which makes transfer of learning from the classroom to the real world quite difficult. The limitations attributed to the structural syllabus led to an alternative approach where the point of departure became situational needs rather than grammatical units.

The underlying premise is that language is related to the situational contexts in which it occurs. The designer of a situational syllabus tries to predict those situations in which the learner will find him/herself, and applies these situations, for instance; seeing the dentist, going to the cinema and meeting a new student, as a basis for selecting and presenting language content. Unlike structural/formal syllabus, situational syllabus offers the possibility of selecting and sequencing different real life situations rather than different grammatical items, vocabulary topics, life situation. In other words, it is designed in such away to provide realistic situation based on a communicative view of language and experimental theory of language learning. 
A critical review of recent trends in second language syllabus design and curriculum development

The situations are usually presented to the students in form of dialogs (usually at the beginning of the lesson, and it includes listening, memorization as well as provides the students models for student improvisation) and role plays (which are the students expected to create, supply or fill in much of the language that occurs in the situation). The content of situation can be created by materials writer or teachers or taken from real life.

\subsection{Types of Situational Syllabus}

Alexander (1976) differentiates three types of the situational syllabus based on type of information:

$>$ Limbo Situation: In this type, the information of the specific setting is of little importance. For example; the topic of introducing someone at the setting of a dialogue taking place at the stadium. It can be said that the setting is considered irrelevant, i.e. unimportant, because the main important thing is the language focus.

$>$ Concrete Situation: The information is about the specific and concrete setting and the language associated with it. For example: The topic of ordering a meal at a restaurant.

$>\quad$ Mythical Situation: The information depends on fictional story line, frequently with a fictional cast characters in a fictional place.

\subsection{Merits}

It has the potential advantage of tapping students' knowledge of the world as an aid to learning, and also of providing realistic, and hence motivating, materials.

$>\quad$ It also may serve the purpose of bridging cultural gap by various conversations and topics that are implied with typical social conventions and customs of the countries and people the learners are interested in.

$>\quad$ It is manageable to take situational syllabus as a foundation, upon which we can incorporate many other syllabus types, for instance, grammatical/structural, functional/notional syllabi, etc.

$>\quad$ Situational syllabus will have a countless resource to utilize, so as to construct and design a variety of courses without worrying about repetition and boredom.

\subsection{Drawbacks}

$>\quad$ Too much use of predetermined and artificial situations can lead to lack of transfer because students are led to pre-learned routines and patterns of language use rather than creative and negotiated uses of language.

$>\quad$ It is difficult to create authentic language instructional purposes because:

a. The actual patterns of use of native speakers in many situations are still unknown and intuition is not a reliable guide.

b. In addition, even when accurate native speaker norms are available it's extremely difficult to write focused and natural dialogues.

c. A third problem with authenticity in situational content is its tendency to become outdated.

$>\quad$ This syllabus may reflect unwanted foreign language values, in other words it is not culture-free.

$>\quad$ Like structural syllabus, this syllabus also presents sequencing problem. 


\section{Notional Functional Syllabus}

A functional-notional syllabus is based on learning to recognize and express the communicative functions of language and the concepts and ideas it expresses. In other words, this kind of syllabus is based more on the purposes for which language is used and on the meanings the speaker wanted to express than on the forms used to express them. Hedge (2000, p. 246) highlights how the 'communicative revolution' in the 1970s urged educators to go beyond structural analyses of language provided by linguists and start to consider what 'communicative ability' in a language entailed. It became apparent that developing such ability required a different view of language.

\subsection{Underlying theories}

The notional-functional approach draws on theories and descriptions of language that emphasize the functional and social aspects of competence (e.g. Hymes' model of communicative competence and Halliday's functional grammar). These syllabuses consist of a list of functions (e.g. apologizing and requesting) and notions (e.g. past time and possibility) together with the linguistic exponents required to realize them in communication. The methodology employed was typically still PPP, i.e. it was accuracy based. Thus, this approach still involves what White (1988) termed a Type A approach, i.e. one where the objectives are defined in advance and that is essentially 'interventionist' and 'other-directed' (p. 31). The functional view of language went beyond the sentential level, and highlighted the importance of discourse in context (Malinowski, 1923). The importance of context in defining the illocutionary force of any utterance was acknowledged, and it was stressed that knowledge of the structure of written or spoken texts was more useful to language learners than isolated, albeit grammatically correct, sentences.

\subsection{Merits}

The learners learn how to use language to express authentic communicative purposes.

$>\quad$ Learners may be motivated by the opportunity to use language to express their own purposes, ideas and emotions.

$>\quad$ It caters more readily to the teaching of the pragmatic aspects of language, such as the linguistic devices needed to display politeness, and also to the teaching of cultural/ceremonial topics, such as when and how to greet people.

$>$ According to Richards and Rodgers (2001) one of the strengths of notional functional syllabus which has helped the emergence of communicative approaches to language teaching is that it considers the needs of the learners and the meanings that they need to convey.

$>\quad$ It also emphasizes the fact that the students and their communicative purposes are at the very core of the teaching program (Raine, 2010).

\subsection{Drawbacks}

$>$ Functions and notions are quite abstract and some learners may have difficulties thinking of communicative functions outside a specific context.

$>\quad$ Different kinds of structures are often used to express the same communicative function, so that it is difficult to follow a progression from simpler to more complex structures.

$>\quad$ Regarding pragmatic considerations, Raine (2010) states that in NFS the content is not arranged based on the formal structures of language, but they are arranged based on the functions. For this reason, it is difficult to use them for the creation of new sentences. 
$>\quad$ Another shortcoming can be ascribed to Grading. White (1988) states that there are no clear-cut criteria for grading of functions and it mainly depends on the material designer's intuition.

\section{Built-in Syllabus}

It is hypothesized that a human infant is born with an innate predisposition to acquire language or as Corder (1967) calls it built-in syllabus; which means that he must be exposed to language for acquisition process to start: that he possesses an internal mechanism of unknown nature which enables him from the limited data available to him to construct a grammar of a particular language. Recent studies (Littlewood, 1984; Ellis, 1993) show that language learners have their own built-in 'syllabus' which governs both when they learn particular grammatical features and also how they learn them. The research demonstrated what many teachers have long known namely, that students often don't learn the grammar they are taught. It indicates why this is so; learners only internalize those grammar features that they are ready to learn and they learn each feature very gradually, passing through a series of transitional stages.

There are perhaps two ways in which teachers can try to address this problem. The first is to make sure that the teaching syllabus matches the learner's own syllabus. That is, teachers need to teach specific grammatical features when they know that the learners are ready to learn them. The difficulty with this solution is that it is not easy to find out if learners are at a stage of development that will enable them to learn a particular structure. This calls for quite sophisticated diagnosis. Another difficulty is that we still do not have anything like a complete picture of what the learner's syllabus looks like. In short, this solution is probably not very practical. The second solution is to circumvent the problem. We can do this if we direct the teaching of grammar at explicit knowledge rather than implicit knowledge. Explicit knowledge is knowledge about grammar - understanding the rules. Implicit knowledge is knowledge of grammar - knowing the rules in an intuitive way that enables them to be accessed quickly and easily for purposes of communication. It is this kind of knowledge that underlies the learner's built-in syllabus and which is acquired gradually. We can avoid the difficulties of trying to match the teaching syllabus to the learner's syllabus if we make explicit rather than implicit knowledge the target of instruction.

\section{Proportional Syllabus}

The proportional or balanced syllabus, originally proposed by Yalden (1983), is a type of syllabus which offers a close interweaving of structural and non-structural (functional), systematic and non-systematic elements over time (White, 1988). Yalden (1987, pp. 96-97) maintains that, this syllabus "is a model that can be used where neither immersion nor the sheltered classroom format is possible, but where development of overall competence is desirable." This syllabus comprises a number of elements within the main theme acting as a link between the units. This theme is designated by the learners. The syllabus is designed to be dynamic, not static, with adequate room for feedback and flexibility. Yalden's fully developed proportional model encompasses an initial phase which focuses mainly on formal meaning. This phase is more appropriate for true beginners and as the proficiency level of the students' increases, the focus shifts to functional (non-structural) meaning.

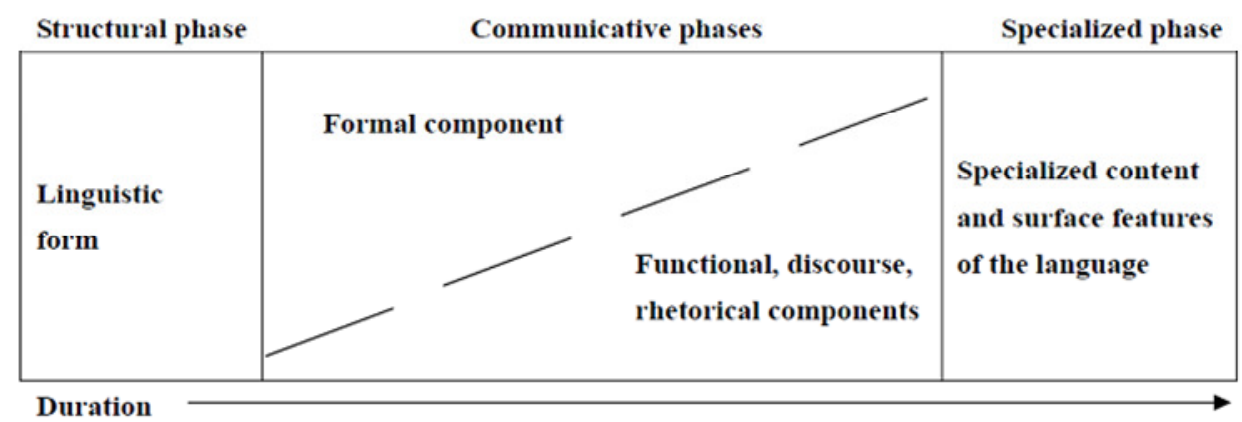

Figure 3. Fully developed proportional model (Yalden, 1987, p. 96) 


\subsection{Merits}

$>\quad$ It gives the course designer the freedom to respond to changing or newly perceived needs in the learners; and meanwhile, it produces a framework for the teacher who wants to start out with a plan.

$>\quad$ A proportional syllabus type can give rise to many kinds of frameworks; and a framework can be designed for most ESL teaching situations.

$>\quad$ This practical approach with its focus on flexibility and cyclical method of language sequencing leading to the recycling of language seems relevant for learners who lack exposure to the target language beyond the classroom (Rabbini, 2002).

$>$ A proportional syllabus allows for classroom content to be dependent upon either the length of time that learners have been studying, or upon their special needs.

\section{Negotiated Syllabus}

Negotiated syllabus is a social and problem-solving model for syllabus design, in which the learner plays the main role and where negotiation is the key concept. This model draws upon general philosophical and educational principles rather than on second language acquisition principles, and its origins can be found in the work of Breen and Candlin (1987), Breen (1984, 1987), and Breen and Littlejohn (2000).

\subsection{The emergence of negotiated syllabus}

There are clearly strong reasons for having a negotiated syllabus. Clarke (1991) sees the interest in negotiated syllabuses arising from humanistic methodologies like community language learning which are very learner-centered, from needs analysis which focuses on learners' needs, from work in individualization and learner autonomy, and from learner strategy research which sees the learner playing a central role in determining how the language is learned. A negotiated syllabus involves the teacher and the learners working together to make decisions at many of the parts of the curriculum design process, making it a 'dynamic' and 'negotiated' syllabus rather than a 'static' and 'imposed' one. It is a way of giving high priority to the recognition of learner needs within a course and to the need to continually adjust courses while they are running to suit changing needs and circumstances. Negotiated syllabuses are also called "process syllabuses" (Breen, 1987). The word process in the term process syllabus indicates that the important feature of this type of syllabus is that it focuses on how the syllabus is made rather than what should be in it.

Breen and Littlejohn (2000) list situations where a negotiated syllabus is almost unavoidable:

$>\quad$ Where the teacher and students have different backgrounds.

$>\quad$ Where time is short and the most useful choices must be made.

$>\quad$ Where there is a very diverse group of students and there is a need to find common ground. 4 Where initial needs analysis is not possible.

Where there is no course book.

$>\quad$ Where the students' past experiences must be part of the course.

$>\quad$ Where the course is open-ended and exploratory.

There is some debate over what aspects of the syllabus could be negotiated. Breen and Littlejohn (2000) see the range of decisions open to negotiation as including some aspects of the curriculum, namely goals, content and sequencing, format and presentation, and monitoring and assessment. A negotiated syllabus tries to integrate 
A critical review of recent trends in second language syllabus design and curriculum development

content (subject-matter) and learning experience, by bridging the gap between what should be taught and what is actually taught. As Breen (1984, p. 56) suggests, a process (negotiated) syllabus is about "who does what with whom, or what subject matter, with what resources, when, how, and for what learning purpose(s)". Hence the focus is not so much on the outcome, but on the process. A process syllabus is personal, intrinsic and is one of 'reality' in process.

\subsection{Merits}

Nation and Macalister (2010) enumerate the followings as the advantages of a negotiated syllabus:

$>$ This syllabus is responsive to the wants of the learners and involves them in the process of learning and decision-making.

$>\quad$ Involving the learners in shaping the syllabus has a strong effect on motivation, satisfaction and commitment to the course. It changes from being the teacher's course to the learners' course.

$>$ If the negotiation is carried out in English, then this may be one of the most involving meaning-focused activities in the program.

$>\quad$ The negotiation also develops learners' awareness of the goals of language-learning activities and how these goals can be achieved.

Breen (1987) also purports that all courses have to adjust in one way or another to the reality of the teaching situation and the negotiated syllabus gives clear recognition to this. Furthermore, a negotiated syllabus will preserve and promote autonomy among learners by granting them a role in decision-making processes.

\subsection{Drawbacks}

Learners may be reluctant to negotiate or to let their classmates negotiate because they feel it should be the teacher's expertise guiding the course:

$>\quad$ Learners may also not know enough of the range of options they could choose from and thus may make unimaginative choices.

$>\quad$ Teachers may feel that using a negotiated syllabus removes too much of their power and status.

$>\quad$ Learners may find it difficult to reach agreement about what they should be doing.

$>\quad$ A fully negotiated syllabus requires considerable teacher skill and time in accessing and producing resources.

$>\quad$ Process syllabi also lack a reasoned proposal for task sequencing, which seems to be based mostly on the learner's wants and wishes.

$>$ Despite recent SLA findings, process syllabi leave no room for focus on form.

$>\quad$ It assumes a high degree of autonomy and a high degree of expertise in learners, which would be unacceptable in some contexts.

\section{Procedural Syllabus}

With the growing dissatisfaction with the Structural and Oral-Situational syllabi, Prabhu who was working at the Regional Institute of English in Bangalore at the time evolved an approach which was called Communicational Teaching Project. Based on this approach, a project named the Bangalore/Madras or the Bangalore Communicational Teaching Project was undertaken in Southern India in the late 1970s and early 
1980s. Johnson (1982) defines procedural syllabus as 'a syllabus of tasks which are graded conceptually and grouped by similarity'. Prabhu recognizes that the acquisition of a linguistic structure is not "an instant, one-step procedure, and claims with Krashen that language form is acquired subconsciously through 'the operation of some internal system of abstract rules and principles' (Prabhu, 1987, p. 70) when the learner's attention is focused on meaning, i.e., task-completion, not language". Prabhu (1987) himself mentions that tasks in a procedural syllabus should be intellectually challenging enough to maintain students' interest, for that is what will sustain learners' efforts at task completion, focus them on meaning and, as part of that process, engage them in confronting the task's linguistic demands.

\subsection{Underlying Theory}

The hypothesis underlying this project was that language form is best learnt when the learner's attention is focused on meaning. More specifically, Grammar-construction by the learner is an unconscious process which is best facilitated by bringing about in the learner a preoccupation with meaning, saying or doing (Prabhu, 1987). In procedural syllabus there is no syllabus in terms of vocabulary or structure. Accordingly, only a few tasks which are sequenced according to difficulty and grouped by similarity constitute this type of syllabus (Mohsenifar, 2008). The cognitive processes, triggered in students' minds through task completion occur at two levels, Conscious and Unconscious. At the conscious level, meaning-building happens when meaning is understood or conveyed. While at the unconscious level, the system-building occurs when grammatical system is developed.

\subsection{Nature of task in procedural syllabus}

Prabhu (1987, p. 24) defines a task as "an activity which required learners to arrive at an outcome from given information through some process of thought, and which allowed teachers to control and regulate that process". Opinion-gap, information-gap and reasoning-gap activities are the kinds of tasks used in the Procedural syllabus. Opinion gaps involve expressing a personal preference, attitude, or feeling when faced with a situation. Information-gaps are operationalized as information sharing between or among learners. Reasoning-gap tasks imply inferring and deducing from, and practical reasoning about a given piece of information.

\subsection{Merits}

$>$ Innovative: the procedural syllabus is novel in comparison to the conventional syllabuses which mainly focused on presenting lists of notions, functions, or structures.

$>$ Focus on meaning: In procedural syllabus, students learn linguistic forms through communication.

$>\quad$ No pre-selection of linguistic items: Procedural syllabus is not structurally or lexically graded. Rather the contents of materials are characterized in holistic units of communication or tasks.

$>$ Naturalness: Prabhu believes that focus on form deters language learning. In his opinion, through focus on meaning, a natural process of learning occurs.

\subsection{Drawbacks}

D The prominence of reasoning: the communicational project relies too much on student reasoning. Prabhu (1987) feels that learners need the security of working with problems in which the answers are clearly right or wrong, and he wishes to encourage guessing and trial-and-error without too much freedom to go astray, so he prefers a small range of possible answers. He claims that open-ended questions make greater demands on the students' language than is appropriate at this early receptive stage.

$>$ The second criticism concerns Prabhu's discouragement of group work. This is because of the fear that 
A critical review of recent trends in second language syllabus design and curriculum development

learners will use their mother tongue, and that learner-learner interaction will promote 'pidginization'. In this approach so much importance is given to message (meaning) that learners felt success is achieved when messages are conveyed, by whatever impoverished and inaccurate linguistic means.

$>\quad$ No rationale exists for the content (task selection) of such a syllabus (Long \& Crookes, 1992).

$>\quad$ Grading task difficulty and sequencing tasks appear to be arbitrary processes, which are left partly to judgments by the classroom teacher (Long \& Crookes, 1992).

$>\quad$ Johnson \& Johnson (1999) believe that the lack of any structural or semantic planning in this syllabus leads to inadequate coverage of the language. So there is interval between students' first exposure to some language items and their mastery. Johnson (1982) points out that implementation of this syllabus results in a long period of 'incubation' between the time that an item is first heard and its mastery by the student.

$>\quad$ Since it is, in fact, a random selection of chunks of the content of other subjects, this syllabus lacks any real life task.

$>\quad$ Markee (1997) also criticizes procedural syllabus for its tasks being teacher-led and less adaptive to learners' needs, and also for being not so much innovative alongside other syllabi such as notional functional and natural approach.

\section{Skill-based Syllabus}

The skill-centered approach to course design has been widely been applied in a number of countries, particularly in Latin America. Students in universities and colleges there have the limited, but important need to read subject texts in English, because they are unavailable in their mother-tongue. As Mohsenifar (2008) puts it, in a "skill-based syllabus", the content of the language teaching is a collection of specific abilities that may play a part in using language. Skill-based syllabi group linguistic competencies (pronunciation, vocabulary, grammar, and discourse) together into generalized types of behavior, such as listening to spoken language for the main idea, writing well-formed paragraphs, giving effective oral presentations, and so on. The primary purpose of skill-based instruction is to learn the specific language skill. A possible secondary purpose is to develop more general competence in the language, learning only incidentally any information that may be available while applying the language skills.

\subsection{What is a skill?}

Krahnke (1987, p. 50) defines a skill as a specific way of using language that combines structural and functional ability but exists independently of specific settings or situations.

\subsection{Underlying theories of skill-based syllabus}

As Richards (2001, p. 160) puts it "approaching a language through skills is based on the belief that learning a complex activity such as " listening to a lecture" involves mastery of a number of individual skills or micro-skills that together make up the activity. Brown (1995, p. 7) points out that the selection of skills is based on the author's perception of their usefulness, whereas their sequencing is usually based on some sense of chronology, frequency, or relative usefulness of the skills. The general theory is that the learning of complex behaviors such as language is best facilitated by breaking them down into small bits (skill), teaching the bits, and hoping that the learner will be able to put them together when actually using them (Cunnigsworth, 1995).

\subsection{Merits}

Richards (2001) Claims made in support of skills-based syllabuses are: 
$>\quad$ They focus on behavior or performance.

$>$ They teach skills that can transfer to many other situations.

$>\quad$ They identify teachable and learnable units.

$>$ Skills-based syllabuses have the advantage of focusing on performance in relation to specific tasks and therefore provide a practical framework for designing courses and teaching materials.

- Krahanke (1987, p. 54) Skill-based content is most useful when learners need to master specific types of language uses, either exclusively or as part of broader competency.

\subsection{Drawbacks}

Darahnke (1987) criticizes this syllabus on the ground that the ability to perform specific tasks in a language is dependent on or independent of overall language proficiency. Indeed, any meaningful second language activity probably improves overall language proficiency, but the more specialized and narrowly defined the instruction; the more unlikely it is to enhance overall proficiency.

$>$ Auerbach (1986) holds that since skill-based instruction is too limited in scope it may program students for particular kinds of behavior or isolate them from achievements and ambitions that the competency doesn't prepare them for (e.g., education rather than entry-level employment).

$>$ According to Willis et al. (2005), a skills-based syllabus is not much more than a list of skills and micro-skills to be practiced. But can we really depend on a syllabus which is merely a list of skills? And, more importantly, in their experiment implementing a skill-based syllabus they observed that teachers felt at sea because they felt they had little or no guidance in the choice of texts to use in order for students to practice these skills.

$>\quad$ The list of skills could not be understood in the same way by all likely participants. If a syllabus aim is to understand common uses of basic verb tenses, there will at least be approximate agreement about what is meant. On the other hand, if the aim is to "infer meaning from context" it is harder to know what would count as success; and if the aim is something as amorphous as "to deal efficiently with customer complaints on the telephone" then one cannot even know for certain that this will be interpreted in the same way by teacher and student, or indeed by either on two consecutive days.

\section{Content-based Syllabus}

Content-based instruction refers to an approach in which teaching is organized around the content rather than around a linguistic syllabus (Richards \& Rodgers, 2001). Krahnke (1987, p. 65) defines content-based syllabus as the teaching of content or information in the language being learned with little or no direct or explicit effort to teach the language itself separately from the content being taught. Content-based syllabus is considered as a sub-category of process-oriented and an analytic syllabus (Nunan, 1988). While Ellis (2003) believes that content-based instruction is a kind of task-based approach, Nunan (1988) maintains that in content-based syllabuses unlike task-based syllabuses which are based on linguistic criteria, the experiential content is derived from subject area.

This content may come from other subjects on the school curriculum, such as science, history, environmental studies, or it might be generated from an analysis of students' interests and needs (Nunan, 2004, p. 130). Snow et al. (1988) believe that the rationale behind the integration of language and content is that language is learned most effectively for communication in meaningful, purposeful social and academic contexts. In real life, people use language to talk about what they know and what they want to know more about, not to talk about language itself. Another underlying rationale is that the integration of content with language instruction provides 
a substantive basis for language teaching and learning. Content can provide both a motivational and a cognitive basis for language learning.

\subsection{Merits}

Nunan $(1988,2004)$ sees the followings as the advantages of content-based syllabuses:

$>$ In comparison with analytic syllabuses which are little more than random collection of tasks, content-based syllabuses enjoy a logical and coherent selection and grading content.

$>\quad$ It shares the advantages of analytical syllabuses.

$>\quad$ Learners learn other aspects of school learning alongside language itself.

$>\quad$ It integrates all the four language skills.

$>\quad$ It actively involves students in the phase of learning.

$>\quad$ It utilizes authentic tasks.

$>\quad$ For all these reasons, it can raise motivation and heighten the engagement of the learner in his or her own learning process.

\subsection{Drawbacks}

$>\quad$ Ellis $(2003$, p. 235) believes that content-based courses might not result in learners achieving high levels of grammatical and sociolinguistic accuracy.

$>\quad$ Brown (2007) argues that teachers can be easily deterred by the demands of content knowledge and discouraged by the amount of preparation they must do. Furthermore, they do not feel that they are qualified to teach content area. Teachers may also get too concerned with content area teaching and neglect teaching related language skills. In other words, the main purpose of content-based instruction is to enhance English language development through content areas, not content learning per se.

$>\quad$ Short (1993) mentions that the difficulty with assessment centers on isolating the language features from the content objectives; in order that, one do not adversely influence the other.

\section{Task-based Syllabus}

\subsection{Underling theory of task-based learning}

According to Krahnke (1987, p. 59) "The primary theory of learning underlying task-based instruction is Krashen's acquisition theory (Krashen, 1982). Acquisition theory argues that the ability to use a language is through exposure to the language and participation in using it. Nunan (2001) also asserts that task-based syllabuses offer a specific realization of communicative language teaching and differs from the previously proposed syllabuses like structural and functional notional syllabuses on the ground that task-based syllabuses start with needs analysis. This needs analysis results in a list of the target tasks that the learners need to carry out in real-life situations such as going through a job interview, completing a credit card application, and finding one's way from a hotel to a subway station.

\subsection{Definition of a task}

Skehan (2003) defines task s an activity in which, a) Meaning is primary. b) Learners are not given other peoples' meaning to regurgitate. c) There is some sort of relationship to comparable real world activities. d) Task 
Rajaee Nia, M., Abbaspour, E., \& Zare, J.

completion has some sort of priority. e) The assessment of the task is in terms of outcome. Nunan (1988 pp. 45-46) cites Candlin (1987) who mentions the characteristics of a good task, some of which have been listed below. A good task should:

$>$ Promote attention to meaning, purpose, negotiation;

$>$ Encourage attention to relevant data;

$>$ Draw objectives from the communicative needs of learners;

$>$ Define a problem to be worked through by learners, centered on the learners but guided by the teacher; and

$>$ Provide opportunities for meta-communication and meta-cognition (i.e. provide opportunities for learners to talk about communication and about learning).

\subsection{The psycholinguistic rationale for TBLT}

Raya quotes Ellis (2009) that the psycholinguistic rationale for TBLT is that:

L Learners have their own built-in syllabus, which directs how they gradually learn the L2 systems.

$>$ The primary goal of any form of language instruction is the development of implicit knowledge as, without this, learners will not be able to communicate effectively.

Implicit knowledge can best be achieved by providing learners with opportunities to experience the L2 as a communicative tool.

$>$ To assist learning, instruction needs to draw learners' attention to form while they are communicating through what is known as focus on form. The learning that results is incidental rather than intentional.

\subsection{Merits}

D As Krahnke (1987, p. 60) says "the intent of task-based learning is to use learners' real-life needs and activities as learning experiences, providing motivation through immediacy and relevancy...."

> In addition, task-based language instruction can be the vehicle for instruction in other types of content or knowledge at the same time as it addresses language acquisition" (Krahnke, 1987, p. 61).

- Krahnke (1987) mentions that task-based learning "can also be valuable for learners who have a clear and immediate need to use the language for well-defined purposes.

> Task-based learning can be especially useful for learners who are not accustomed to more traditional types of classroom learning or who need to learn cognitive, cultural, and life skills along with the language." (p. 61)

$>$ Task-based syllabuses can be very useful in ESP courses.

$>$ It also helps language learners to acquire language instead of learning it.

> In this regard, Nunan $(2004$, p. 30$)$ maintains that "in a task-based syllabus, grammatical and functional items will reappear numerous times in a diverse range of contexts".

\subsection{Drawbacks}

$>$ It ignores addressing explicit meta-linguistic knowledge, or the ability to make descriptive or 
A critical review of recent trends in second language syllabus design and curriculum development

prescriptive statements about language and manipulate language as an end in itself. Or in Nation and Macalister's (2010) words, it focuses on fluency at the expense of accuracy.

$>\quad$ Another problem discussed by Krahnke (1987, p. 61) is that task-based learning requires a high level of creativity and initiative on the part of the teacher.

> Krahnke (1987) also believes that the evaluation in task-based syllabuses can be difficult because the nature of tasks or tasks-based learning makes it difficult to measure learners' knowledge by the utilization of traditional discrete-point achievement tests.

\section{Lexical Syllabus}

Emergence of lexical syllabus was a reaction against traditional structural syllabus. The basic concept on which this syllabus rests is that students must be able to understand and use lexical phrases such as chunks, prefabricated patterns, and collocations. In this regard, Lewis (1993, p. 95) says that "an important part of language acquisition is the ability to comprehend and produce lexical phrases as unanalyzed wholes, or "chunks," and that these chunks become the raw data by which learners perceive patterns of language traditionally thought of as grammar."

\subsection{Criteria for the selection of lexical items}

$>$ Frequency: By using language corpora syllabus designer lists the most frequent expressions in the language.

$>$ Teachability: The selected most frequent words will be piloted and the words which are difficult to manage in the classroom will be discarded.

$>$ Authenticity: The lexical items selected in the Lexical Syllabus are taken from authentic texts produced by language users in their everyday lives.

$>$ Coverage: This syllabus tries to select lexical items which are generic and are not context-specific.

$>$ Similarity: Where possible, lexical syllabus takes advantage of cognates or similar terms shared by both languages. For example, the terms "mother" and "father" are similar in all Indo-European languages.

\subsection{Merits}

Sinclair and Renouf (1988) list the five advantages of a lexical syllabus as follows:

$>$ Practiality: Since it employ the most common words of the language, learners can benefit from them in their daily life.

$>$ Efficiency: One of the advantages of a lexical syllabus is that it only offers to the learner things worth learning. One of the advantages of a lexical syllabus is that it only offers to the learner things worth learning.

$>\quad$ Utility: It does not solely present learners with a discrete list of lexical items to be memorized. What is important in this syllabus is to have the learners grasp the function and usage of those chunks. The emphasis shifts from constructing messages to delivering them, and delivering them to maximum effect, and to achieving communicative goals.

$>$ Authenticity: All of the teaching materials are selected from authentic language use. For the reading materials, authentic documents for communication purposes are selected. For listening materials, 
natural utterances in communication are recorded.

Flexibility in implementation: The lexical syllabus is an independent syllabus. It is unrelated by any principles to any methodology, which ensures that lexical syllabus could adopt any other teaching practice. Certain methodological options can readily adapt to it.

\subsection{Drawbacks}

$>$ The use of the inflected forms of the base-forms of words in word lists, to some extent, does not correspond to natural language use.

$>$ A high percentage of words of high frequency are in fact function words which are not that useful to negotiate the intended message.

$>$ In lexical syllabus, grammar seems to be dealt with intuitively or decided by the words used. When it comes to the instruction from the teachers, aspects concerned with grammar are not an easy question.

$>$ If learners need thousands if discrete lexical items, each of which needs to be taught, it is impossible that every item needs to be formally taught in language classroom. The majority of language acquired by the learner must come from sources other than formal teaching (Lewis, 2002).

\section{Cultural Syllabus}

Whether culture should be taught as a separate subject is a controversial issue in the field second language education. As Abbaspour et al. (in press) concluded, culture and language are inseparable and culture learning must be an integral part of language learning. Along the same line, Brown (2007, p. 165) maintains that, "A language is part of a culture and culture is part of language; the two are intricately interwoven so that one cannot separate the two without losing the significance of either language or culture".

Stern (1983) proposes a four-dimensional model in which he integrates four major areas or "syllabi", namely, the Language Syllabus, encompassing both structural and functional aspects of the language; the Communicative/Experiential Syllabus, which specifies "fields of experience" for project-based language activities; the Culture Syllabus, containing topics and applications for the development of socio-cultural knowledge and awareness. A cultural syllabus often addresses the non-verbal as well as the verbal components of language and how these may be incorporated into language lessons by teachers.

\subsection{Merits}

Fleet (20o6) enumerates the benefits of a cultural syllabus as follows:

$>$ It increases communicative competence: Culture, as part of the language syllabus, is instrumental in enhancing communicative competence. Peterson and Coltrane (2003) assert that "in order for communication to be successful, language use must be associated with other culturally appropriate behavior" (p. 2)

$>$ It allows more authentic language learning: The language learning experience becomes more real, more purposeful and more authentic for learners when they are taught the cultural contexts of the language itself (Peterson \& Coltrane, 2003).

$>$ It motivates learners to learn languages: Teaching about the target culture when teaching the target language boosts the interest of students and acts as a motivator.

$>$ It instills an intercultural competence: If language students are taught the target culture and the language simultaneously, it may affect their perceptions and attitudes toward the target language 
speakers and their culture positively.

\subsection{Drawback}

Stern (1992, p. 207) identifies the major problems that might occur while implementing a cultural syllabus as follows:

$>\quad$ The vastness of the culture concept;

$>\quad$ The problem of goal determination and the lack of accessible information;

$>$ Questions of syllabus design and the difficulty of according an appropriate place to culture in a predominantly language oriented approach; and

$>$ Questions of teaching procedures and difficulty of handling substantive subject-matter in a mainly skill-oriented program.

\section{Multi-dimensional Syllabus}

So far we have looked at syllabuses as they are mutually exclusive; that a course designer would base the course on only one parameter (being the structure, the situation, the task, the function etc.) as the unit of organization, and not the amalgamation of all these parameters. However, there are various ways in which different syllabus specifications may be combined to create what is sometimes referred to as the 'multidimensional syllabus' (Johnson 2009). The underlying principle of multi-dimensional syllabus is that, unlike other syllabuses which solely rely on one specification, there should be flexibility to change the central point of the teaching material as the goes on (Mohsenifar, 2008).

This flexibility in the specifications of the unit of organization can lead to syllabuses where the unit of organization shifts at different points in the course. One example in the early days of notional functional syllabus is Morrow and Johnson (1979) cited in Johnson (2009). These are functionally based materials, with each teaching unit covering a functional area. But since it is recognized that functional organization leads the learner to encounter structural diversity (a number of different grammatical structures occurring in the same functional unit), a number of structurally-oriented units are interspersed to bring together grammatical points which might otherwise not receive sufficient coverage. A more frequent type of multi-dimensionality in recent times involves shifts of focus within each teaching unit. Thus, sections of a unit will focus on a structure, others on a function, and still others perhaps in a syllabus of learning procedures.

\subsection{Merits}

$>\quad$ Sinclair and Renouf (1988, p. 144) note that this serves to show that "language has many facets, and corresponds partially to many different patterns of organization"

$>\quad$ There is also the potential pedagogic advantage of providing variety, with the shift of focus changing at regular points (Johnson, 2009).

\subsection{Drawbacks}

$>$ Johnson (1982, p. 68) notes that over-frequent shifts of focus may confuse the learner.

$>\quad$ Sinclair and Renouf (1988), who consider this, issue from the point of view of teaching structures and lexis, note that "it is exceptionally difficult to teach an organized syllabus of both grammar and lexis at the same time" (p. 143). The variety may, they say, be bewildering, "and the actual coordination minimal". 


\section{Conclusion}

A quick glimpse at the literature of language teaching would reveal that a countless number of books and research articles, addressing the issue of syllabus design and curriculum development, have been published in the past decades. Though briefly, the approaches depicted here all offer valuable insights into designing a syllabus. Each of these syllabuses fits a specific context and purpose, and caters for specific learners with specific needs. To borrow Hutchinson and Waters (1987, p. 51) words, "It is wise to take an eclectic approach, taking what is useful from each theory and trusting also in the evidence of your own experience as a teacher". By taking an eclectic approach, the syllabus designers can both do away with the disadvantages of each approach and meet the specific needs of the learners.

\section{References:}

Abbaspour, E., Rajaee Nia, M., \& Zare, J. (in press). How to integrate culture in second language education? Journal of Education and Practice.

Alexander, L. G. (1976). Where do we go from here: A reconsideration of some basic assumptions affecting course design. ELT Journal, 30(2), 89-103. <http://dx.doi.org/10.1093/elt/XXX.2.89>

Auerbach, E. R. (1986). Competency-based ESL: One step forward or two steps back? TESOL Quarterly, 20(3), 411-415. <http://dx.doi.org/10.2307/3586292>

Breen, M. (1984). Process syllabuses for the language classroom. In C. J. Brumfit (Ed.), General English syllabus design (pp. 75-82). London: Pergamon Press \& the British Council.

Breen, M. (1987). Contemporary paradigm in syllabus design. Language Teaching, 20, 81-91. <http://dx.doi.org/10.1017/S0261444800004365>

Breen, M. P., \& Littlejohn, A. (2000). Classroom decision-making. Cambridge: Cambridge University Press.

Breen, M., \& Candlin, C. N. (1987). Which materials? A consumer's and designer's guide. In L. Sheldon (Ed.), ELT textbooks and materials: Problems in evaluation and development (ELT document 126, pp. 13-28). London: Modern English Publication.

Brown, H. D. (2007). Principles of language learning and teaching (5th ed.). New York: Longman.

Brown, J. D. (1995). The elements of language curriculum. New York: Newbury House.

Clarke, D. F. (1991). The negotiated syllabus: What is it and how is it likely to work? Applied Linguistics, 12(1), 13-28. <http://dx.doi.org/10.1093/applin/12.1.13>

Corder, S. P. (1967).The significance of learners' errors. International review of Applied Linguistics, 5, 161-170.

Cunningsworth, A. (1995). Choosing your coursebook. London: Macmillan.

Ellis, R. (1993). The structural syllabus and second language acquisition. TESOL Quarterly, 27, 91-113. $<$ http://dx.doi.org/10.2307/3586953>

Fleet, M. (2006). The role of culture in second or foreign language teaching: Moving beyond the classroom experience. ERIC Database. Retrieved August 4, 2012, from http://www.eric.ed.gov/PDFS/ED491716.pdf

Hartwell, P. (1985). Grammar, grammars, and the teaching of grammar. College English, 42, 105-127. $<$ http://dx.doi.org/10.2307/376562>

Hedge, T. (2000). Teaching and learning in the language classroom. Oxford: Oxford University Press.

Hutchinson, T., \& Waters, A. (1987). English for specific purposes: A learning-centered approach. London: Longman. <http://dx.doi.org/10.1017/CBO9780511733031>

Johnson, K. (1982). Communicative syllabus design and methodology. London: Pergamon Press.

Johnson, K. (2009). Foreign language syllabus design. In K. Knapp \& B. Seidlhofer (Eds.), Handbook of foreign language communication and learning (pp 309-340). Berlin: Mouton de Gruyter.

Johnson, K., \& Johnson, H. (1999). Encyclopedic dictionary of applied linguistics: A handbook for language teaching. Oxford: Blackwell Publications. 
A critical review of recent trends in second language syllabus design and curriculum development

Johnson, K., \& Morrow, K. (1979). Approaches: A language activation course for intermediate students. Cambridge: Cambridge University Press.

Krahnke, K. (1987). Approaches to syllabus design for foreign language teaching. Englewood Cliffs: Prentice Hall.

Krashen, S. (1982). Principle and practice in second language acquisition. Oxford: Pergamon Press.

Lewis, M. (1993). The lexical approach. London: Language Teaching Publications.

Lewis, M. (2002). Implementing the lexical approach: Putting theory into practice. Boston, MA: Heinle.

Littlewood, W. (1984). Foreign and second language learning: Language acquisition research and its implications for the classroom. Cambridge: Cambridge University Press.

Long, M., \& Crookes, G. (1992). Three approaches to task-based syllabus design. TESOL Quarterly, 26, 27-56. $<$ http://dx.doi.org/10.2307/3587368>

Malinowski, B. (1923). The problem of meaning in primitive languages. In C. K. Ogden \& I. A. Richards (Eds.), The meaning of meaning (pp. 146-152). London: Routledge.

Markee, N. (1997). Managing curricular change. Cambridge: Cambridge University Press.

Mohsenifar, M. (2008). Influential types of syllabuses within educational contexts. Pakistan Journal of Social Sciences, 5, 379-384.

Nation, I. S. P., \& Macalister, J. (2010). Language curriculum design. New York: Routledge.

Nunan, D. (1988 ). Syllabus design. Oxford: Oxford University Press.

Nunan, D. (2001). Second language acquisition. In R. Carter \& D. Nunan (Eds.), The Cambridge guide to teaching English to speakers of other languages (pp. 87-92).Cambridge: Cambridge University Press. $<$ http://dx.doi.org/10.1017/CBO9780511667206.013>

Nunan, D. (2004). Task-based language teaching. Cambridge: Cambridge University Press. $<$ http://dx.doi.org/10.1017/CBO9780511667336>

Peterson, E., \& Coltrane, B. (2003). Culture in second language teaching. CAL Digest, 3(9), 1-6.

Prabhu, N. S. (1987). Second language pedagogy. Oxford: Oxford University Press.

Rabbini, R. (2002). An Introduction to Syllabus Design and Evaluation. The Internet TESL Journal, 8(5).

Raine, P. (2010). A discussion of the notional-functional syllabus. Unpublished manuscript, University of Birmingham, Birmingham, UK.

Raya, M. J. (2009). Task-based language learning: An interview with Rod Ellis. Greta Journal. Retrieved June 5, 2012, from http://gretajournal.com/wordpress/wp-content/uploads/2009_5\%281\%29.pdf

Richards, J. (2001). Curriculum development in language teaching. Edinburgh: Cambridge University Press. $<$ http://dx.doi.org/10.1017/CBO9780511667220>

Richards, J., \& Rodgers, T. (2001). Approaches and methods in language teaching. NewYork: Cambridge University Press. <http://dx.doi.org/10.1017/CBO9780511667305>

Short, D. J. (1993). Assessing integrated language and content instruction. TESOL Quarterly, 27(4), 627-656. $<\underline{\text { http://dx.doi.org/10.2307/3587399> }}$

Sinclair, J. M., \& Renouf, A. (1988). A lexical syllabus for language learning. In R. Carter \& M. McCarthy (Eds.), Vocabulary and language teaching (pp. 141-160). London: Longman.

Skehan, P. (2003). Task-based instruction. Language Teaching, 36, 1-14. <http://dx.doi.org/10.1017/S026144480200188X>

Snow, M. A., \& Brinton, D. (1988). Content-based language instruction: Investigating the effectiveness of the adjunct model. TESOL Quarterly, 22(4), 575-592. <http://dx.doi.org/10.2307/3587256>

Stern, H. H. (1983). Toward a multidimensional foreign language curriculum. In R. G. Mead (Ed.), Foreign languages: Key links in the chain of learning (pp. 120-141). Middlebury: Northeast Conference.

Stevick, E. W. (1972). Evaluation and adapting language materials. In H. B. Allen \& R. N. Campbell (Eds.), Teaching English as a second language (pp. 102-120). New York: McGraw-Hill.

White, R. V. (1988). The ELT curriculum: Design, innovation and management. Oxford: Blackwell.

Wilkins, D. A. (1976). Notional syllabuses. Oxford: Oxford University Press.

Wilkins, D. A. (1981). Notional syllabuses revisited. Applied Linguistics, 2(1), 83-89. <http://dx.doi.org/10.1093/applin/2.1.83> 
Rajaee Nia, M., Abbaspour, E., \& Zare, J.

Willis, J., \& Skelton, J. (2005). Approaches to syllabus specification course and syllabus design. Retrieved June 15, 2012, from http://www.philseflsupport.com/cds1.html

Yalden, J. (1983). The communicative syllabus: Evolution, design and implementation. Oxford: Pergamon.

Yalden, J. (1987). The principles of course design for language teaching. Englewood Cliffs: Prentice-Hall. 